\title{
Management of Post-Partum Uterine Prolapse in Murrah Buffalo: A Case Report
}

\author{
Narendra Pratap Singh ${ }^{1}$, Amit Baranwal ${ }^{2}$ and Vinod Kumar ${ }^{3}$
}

${ }^{1}$ ICAR- Indian Veterinary Research Institute, U.P, India

${ }^{2}$ Division of Animal Genetics and Breeding, ICAR-Indian Veterinary Research Institute, U.P, India

${ }^{3}$ Department of Veterinary Surgery \& Radiology, West Bengal University of Animal and Fishery Sciences, Kolkata, India

*Corresponding author

\section{A B S T R A C T}

\section{Keywords}

Clinical management, Murrah buffalo, Uterine prolapse

Article Info

Accepted:

12 July 2018

Available Online:

10 August 2018
The present case reports on management of complete uterine prolapse in Murrah buffalo in her $4^{\text {rth }}$ lactation at Astron Dairy Farms, Roorkee, Uttarakhand. The animal completely recovered after proper treatment, management and care. The condition of uterine prolapse as well as the post case precautions for the diseased animal was followed up and presented the positive result of complete recovery without any complication.

\section{Introduction}

Indian buffaloes are important source of milk supply today and their yield has approximated almost three times to that of the cattle production in India. More than half of the total milk produced $(55 \%)$ in the country was contributed by the 47.22 million milch buffaloes. Prolapse of the uterus is one of the most commonly observed clinical conditions in large ruminants like cows and buffaloes. It generally occurs during the 3rd stage of parturition or immediately after it in buffaloes, but in some rare cases it may be seen 24 hours to 48 hours after parturition. However, it is commonly found as a complication of the third stage of labour in the buffaloes (Joseph et al., 2001). The reproductive performance in buffalo has also been reported to be poor due to various diseases of the reproductive system which also includes cases of genital prolapse (Rao and Sreemannarayana, 1983; Akhtar et al., 2012). Samad et al. (1987) reported the incidence of genital prolapse to be as high as 
42.9\% among various obstetrical problems in buffaloes. Although, the prolapse of various elements viz. vaginal, cervico-vaginal, uterus and rectum has been reported in buffaloes (Sah and Nakao, 2003; Singh et al., 2011; Kumbhar et al., 2009 and Patil et al., 2011), the cervico-vaginal prolapse together with prolapsed rectum is a rare disorder. Etiological factors of pre-partum vaginal prolapse in buffaloes has been attributed to nutritional imbalances (Kelkar et al., 1989; Ahmed et al., 2005), hormonal imbalances (Galhotra et al., 1991), seasonal and managemental factors (Mishra et al., 1998; Gurcharan et al., 2003; Akhtar et al., 2010) as well as hereditary predisposition (Nanda and Sharma, 1982).

Hormonal changes that occur during last trimester of pregnancy, especially an increase in the level of estrogen and the production of relaxin leads to relaxation of the pelvic ligaments and surrounding soft tissue structures (Wolfe, 2009).

The present communication reports a case of post partum uterine prolapse in Murrah buffalo with its successful clinical management.

\section{Case history and clinical observation}

A 9 year old buffalo was attended at Astron Dairy Farms, Roorkee, Uttarakhand for treatment of complete uterine prolapse which occurred at the time of calving. History of the animal revealed that it was her $4^{\text {th }}$ parturition. On gynaeco-clinical examination of the buffalo in standing position displayed complete prolapse of uterus along with retained fetal membranes hanging below the hock joint (Figure 1). The ocular mucous membrane was slightly congested. The animal was showing signs of discomfort and also exhibited mild and intermittent straining. Though the animal was temporarily off feed, the physiological parameters like temperature, pulse and respiratory rate were within the normal range.

\section{Treatment and Discussion}

The buffalo was securely restrained in a travis and was administered epidural anaesthesia (2\% lignocaine, $5 \mathrm{ml}$ ). The animal was then allowed to go into recumbent position after which the procedure for treatment was started. The hanging portion of the placenta was removed manually.

Fig.1\&2 Uterine prolapse with retained fetal membranes and showing clinical management of uterine prolapse

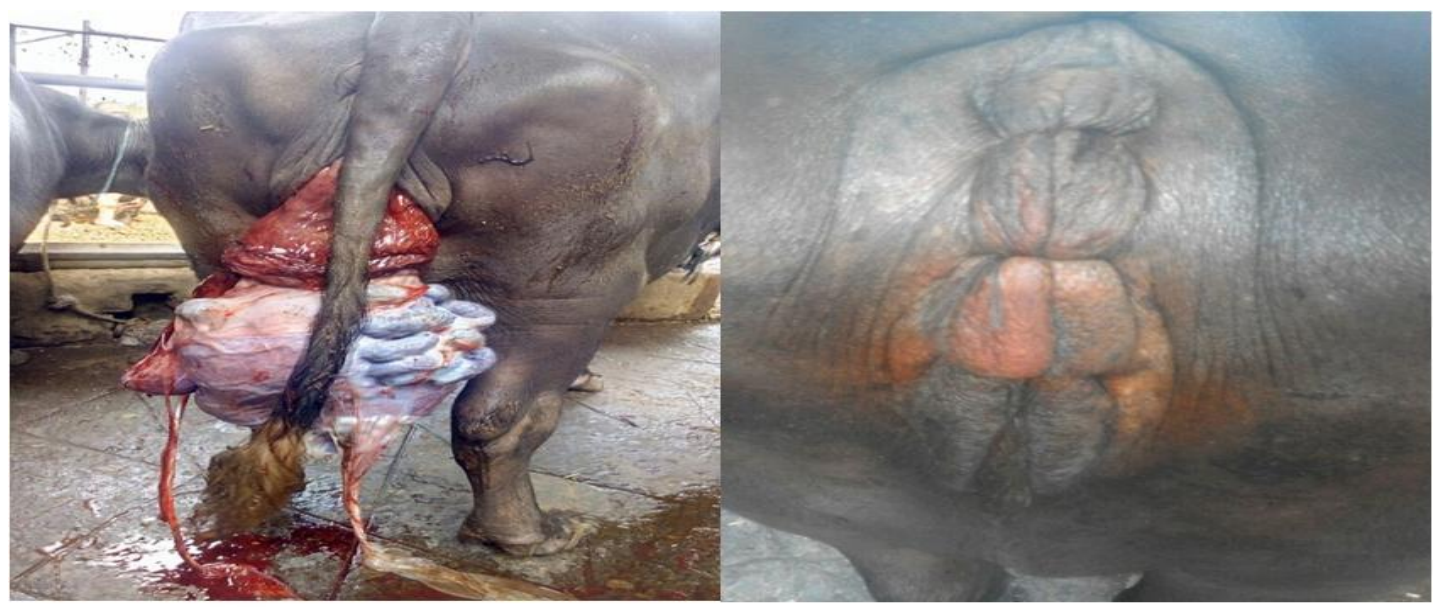

Figure. 1
Figure.2 
Fig.3\&4 Showing clinical management of uterine prolapse and successful clinical management of uterine prolapse

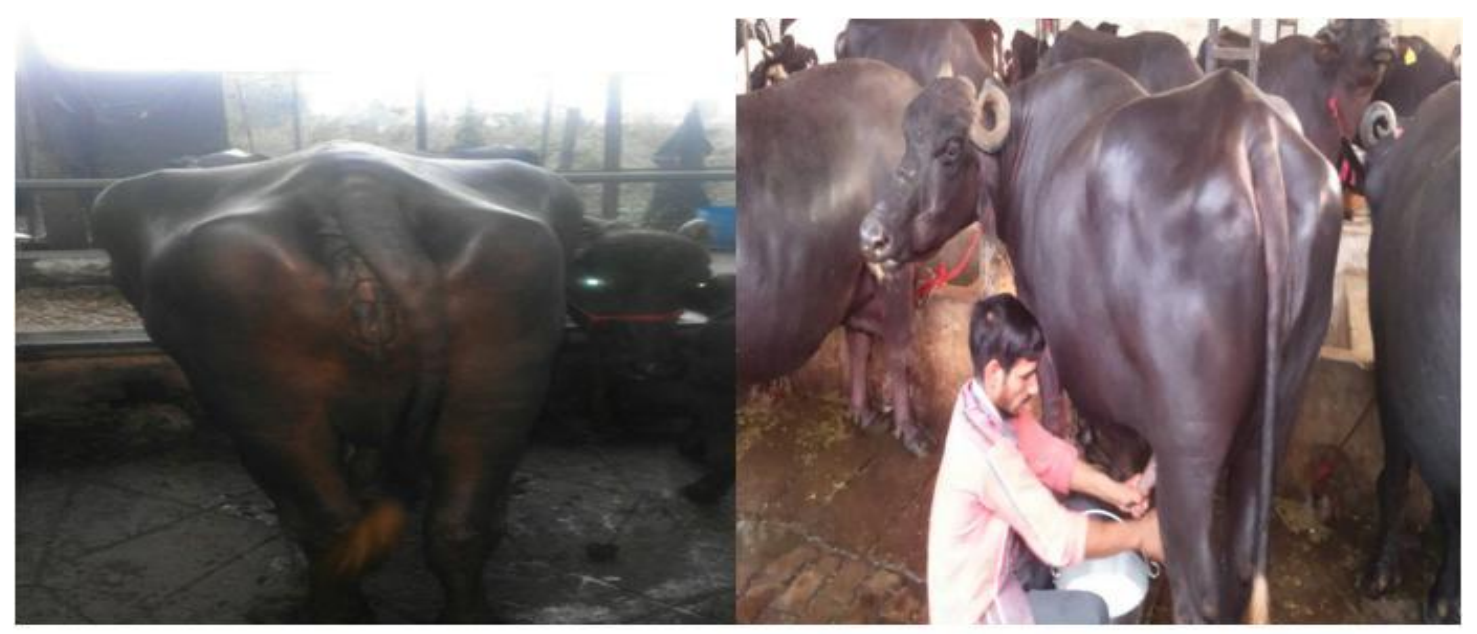

Figure.3

The Prolapsed mass was washed free of dirt and debris with $0.5 \%$ potassium permanganate solution. The protruding mass was gently elevated above the ischial arch to empty the bladder. After applying mild antiseptic cream (Soframycin) the prolapsed mass was reduced by gentle pushing action with fisted hand while slowly elevating the mass from below simultaneously with the palm of other hand, thereby replacing the cervix and vagina to their original position.

Recurrence of prolapse was prevented by applying simple interrupted suture (Figure 2). The animal was administered injection (inj.) 5\% Dextrose saline, 2.5 litres intra venously (i/v), Calcium borogluconate (mifex) $450 \mathrm{ml}$ i/v was administered on the 1st day following which administration of inj Ampicillin $2.25 \mathrm{gm}+$ Cloxacillin $2.25 \mathrm{gm}$. was injected intra muscularly (i/m), Chlorphenaramine maleate 50 mg. i/m, inj. Styptochrome $25 \mathrm{mg} \mathrm{i} / \mathrm{m}$. and Meloxicam $0.5 \mathrm{mg} / \mathrm{kg}$ body weight was repeated for 5 days.

Topical application of topicure herbal spray was used externally over the vulval lips as a fly repellant. The different vital parameters were monitored regularly to ascertain any abnormal
Figure.4

changes. Buffalo recovered completely and stood up on its legs after 4 hours of treatment and was able to take feed normally. No further symptoms of prolapse or any clinical manifestations were observed during postoperative treatment. There was proper urine flow and no pus discharge with uterine tonicity was observed on rectal examination. The suture material was removed after 10 days. Buffalo recovered completely without any future reproductive complication (Fig. 3 and 4).

The animal showed signs of heat 48 days after the last treatment and was successfully inseminated. The usual sequel of uterine prolapse is haemorrhage, shock, septic metritis, peritonitis, infertility or death. But in this case, after detaching the fetal membranes, the prolapsed mass became lighter and less voluminous, so it was easy to riposte as described by Bhoi and Parekar (2009).

\section{Acknowledgement}

The authors acknowledge the help provided by Rajesh kumar and Krishan kumar, Technical assistant in carrying out the treatment and grateful to the Director, Astron Dairy Farm, Roorkee for financial support. 


\section{References}

Ahmed S.I., L.A. Ahmad, N.A. Lodhi and H.A. Samad. 2005. Clinical, haematological and serum macro mineral contents in buffaloes with genital prolapse. Pak. Vet. J., 25: 167- 170.

Akhtar, M.S., L.A. Lodhi, I. Ahmad, Z.I. Qureshi, and G. Muhammad. 2012. Serum ovarian

steriod hormones and some minerals concentration in pregnant Nili-Ravi buffaloes with or without pre-partum vaginal prolapse. Pak. Vet. J., 32: 265268.

Akhtar, M.S., L.A. Lodhi, I. Ahmad, Z.I. Qureshi, and G. Muhammad. 2010. Incidence of pre-partum vaginal prolapse in Nili-Ravi buffalo under two different agro-ecological zones of Punjab, Pakistan, p. 785-788. In Proceedings of 9th World Buffalo Congress, Buenos Aires, Argentina.

Bhoi, D.B. and S.S. Parekar. 2009. Post-Partum Uterine Prolapse in a Non-descript Buffalo. Veterinary World, 2(4):149.

Galhotra, M.M., G.C. Georgie and V.P. Dixit. 1991. FSH, LH and prolactin in antepartum vaginal prolapse of buffaloes (Bubalus bubalis) in relation to cortisol and degree of stress. Indian Vet. J., 68: 332-335.

Gurcharan, S., S.S. Sidhu and H.K. Verma. 2003. Incidence of reproductive disorders of buffaloes in different zones of Punjab state. Punjab Agri. Uni. J. Res., 40: 79-80.

Joseph, C., K. Kulasekar, S. Balasubramanian, D. Kathiresan, C. Veerapandian and S.R. Pattabiraman. 2001. An unusual complication of post-partum uterine prolapsed in a she buffalo-a case report.
Indian Vet. J., 78: 57-58.

Kelkar, M.A., S.K. Khar and V.M. Mandakhot. 1989. Studies on the ante partum prolapse of the vagina in buffaloes and plasma trace element concentrations. Archiv. Fur. Experimentelle Veterinarmedizin, 43: 315- 318.

Kumbhar, U. B., A. A. Suryawanshi, J. B. Mulani and D. S. Raghuwanshi. 2009. Clinical management of post-partum eversion of uterus in Marathwadi buffalo. Veterinary World, 2(5): 202.

Nanda, A.S. and R.D. Sharma, 1982. Incidence and etiology of pre-partum prolapse of vagina in buffaloes. Indian J. Dairy Sci., 35: 168- 171.

Patil, A. D., U. B. Kumbhar and K. Thorat. 2011. Pre-partum rectal prolapse in a buffalo. Intas Polivet, 12(1): 46-47.

Rao, A.V.N. and O. Sreemannarayana. 1983. Clinical analysis of reproductive failure among female buffaloes (Bubalus bubalis) under village management in Andhra Pradesh. Theriogenology, 18: 403-411.

Sah, S.K. and T. Nakao. 2003. Some characteristics of vaginal prolapse in Nepali buffaloes. J. Vet. Med. Sci., 65: 1213-1215.

Singh, B., K. P. Singh, S. V. Singh, J. P. Singh and H. N. Singh. 2011. Post-partum cervicovaginal prolapse in a buffalo. Intas Polivet, 12(1): 32-33.

Samad, H.A., C.S. Ali, N.U. Rehman, A. Ahmad and N. Ahmad. 1987. Clinical incidence of reproductive disorders in buffaloes. Pak Vet. J., 7: 16-19.

Wolfe, D.F. 2009. Medical and surgical management of vaginal prolapse in cattle. In Proceedings of 81st Annual Western Veterinary Conference, USA.

\section{How to cite this article:}

Narendra Pratap Singh, Amit Baranwal and Vinod Kumar. 2018. Management of Post-Partum Uterine Prolapse in Murrah Buffalo: A Case Report. Int.J.Curr.Microbiol.App.Sci. 7(08): 18161819. doi: https://doi.org/10.20546/ijcmas.2018.708.208 